\title{
A Proposed Application based on Mobile Learning Techniques to Manage Electronic Tests
}

\author{
Rasha Kandel M. Arafa \\ Department of Computer \\ Teacher Preparation, Faculty \\ of Specific Education \\ Damietta University \\ Damietta, Egypt
}

\author{
Elsaeed Elsaeed Mohamed \\ Abd Elrazek \\ Department of Computer \\ Teacher Preparation, Faculty \\ of Specific Education \\ Damietta University \\ Damietta, Egypt
}

\author{
M. Z. Rashad \\ Department of Computer \\ Science, Faculty of Computer \\ Science and Information \\ Technology, Mansoura \\ University, Mansoura, Egypt
}

\begin{abstract}
The current research aims to identify the effectiveness of a proposed application based on mobile educational techniques for the management of electronic tests. The sample consisted of a group of students of the fourth division of computer teacher preparation department in the Faculty of Specific Education in Damietta during the academic year 2018/2017) and the number (20).The results of the current research showed that There are statistically significant differences at level 0.05 between the average scores When pre and post applying the achievement test. The results indicated that There are positive trends among experimental group students (which study the network course using the proposed system) towards the use of the proposed system and there is the effectiveness of the proposed system to assess the learner and to get feedback and show the shortcomings of the learner that measure target at 0.05 level of significance.
\end{abstract}

\section{Keywords}

Mobile Learning (ML) - Electronic tests - E-evaluation -

Mobile Application

\section{INTRODUCTION}

Technology played an important role in the educational process. E-learning has become one of the most common teaching and learning methods through the expansion of spatial and temporal barriers. Many e-learning systems have been developed over the past decade. Learning management systems are able to support online training with different levels of accuracy and formalization, which focus on automating certain aspects of the design, implementation and evaluation process. In the past decade, open source software has become one of the most widely used platforms among software users, developers and practitioners for personal use as well as professional use. LMS has emerged as a very practical solution for many schools, colleges and universities, especially universities from 8-10 years. LMS has helped organizations deliver content or instructional design for different courses and play a vital role in serving educational and educational goals [1]. E-learning is one of the areas that can benefit from Semantic Web technologies. This technology has enabled the Semantic Web by a group of appropriate factors, which appear to be strong enough to meet the requirements of e-learning a quick, fair, timely and relevant learning[2]. Mobile learning is a type of e-learning where mobile devices are used where learners are allowed to continue learning at any time and from anywhere outside the boundaries of the institution using mobile devices through mobile phones, smart phones, etc., helping to develop learners 'skills to ensure learners' access To materials and contributions to their learning with the help of portable devices in wireless environments. Mobile devices have become an important part of our daily lives. Devices like smart phones or tablets communicate with a great source of information and enable interaction with others near wherever we go. These devices are available with a significant improvement in memory storage, performance and high data transfer speed, resulting in the use of mobile technologies for educational purposes [3].E-tests are carried out by computer techniques and networks through which all evaluation activities are carried out: preparing and presenting evaluation questions and tasks for students, responding to students, receiving and correcting responses, providing feedback on the answer, assessing their grades, monitoring and interpreting the results of the evaluation, and provide safety measures for all of this in order to maintain privacy.Evaluation in an educational system is an important and fundamental part of its success to ensure the right way to transfer knowledge and ensure that students work correctly and succeed in acquiring the necessary knowledge. In this study, we aim to include semantic web and mobile technologies in the e-learning process, as new components.

\section{RESEARCH HYPOTHESES:}

1. There are no statistically significant differences at level 0.05 between the average scores when pre and post applying the achievement test

2. There are positive trends among experimental group students (which study the network course using the proposed system) towards the use of the proposed system.

\section{SEARCH LIMITS}

\subsection{Geographic boundaries}

The search is limited to Damietta Governorate

\subsection{Time limits}

The academic year 2017-2018

\subsection{Human boundaries}

The current research is limited to a sample of students of the fourth division of the Department of Computer Teacher Preparation, Faculty of Specific Education, and Damietta.

\section{RELATED WORK}

The theoretical framework of this research and associated previous studies will be discussed in the following areas: 


\subsection{The first aspect: Mobile Learning}

M-Learning is the next generation of e-learning. M-Learning is a technology that uses mobile and wireless technologies in learning and teaching. M-Learning enables learners to integrate their learning experiences into a collaborative environment. Currently, the Internet and WWW have improved learning activities that provide a high level of interaction between teachers and learners who are geographically separated. Mobile learning will be the next generation of distance learning [4]. Mobile technology provides the opportunity for people to use their time in the most effective way for different purposes, not least learning. The use of mobile technology allows trainees access to information and tools to help wherever they are. It is time to think of mobile phones as a new form of laptop that has the capabilities to be used in learning processes. Provides a new generation of learning for people of all ages anywhere and anytime. In addition, m-learning offers many advantages including: freedom to study flexibly, low cost and timely application. [5] There is greater learner mobility. Using their mobile phones, students can receive and share notes and materials. It does not need a computer to download notes because a mobile phone with Internet access can perform this function anywhere, anytime. Information can also be transmitted by lecturers to their students using blogs or SMS. [6]

\subsubsection{Studies that dealt with this aspect}

Castillo, A. et.al, (2013) presents MLEA, a mobile learning application that integrates the functionality of Android, Moodle LMS and mobile learning system users. The application is an answer to the preferences of young adult learners of mobile technologies. It also provides that teachers will close the bridge with their students as well as trends in higher education and describe in detail the structure of MLEA design, including the creation of web services through the project pattern $\mathrm{DAO}$ and a factory method to ensure flexibility [7].

Cavus, N. \& Al-Momani, M. (2011) The aim of this study is to improve m-learning systems, in particular to provide the required knowledge for learners with less limitations in terms of devices, sites and networks used. The system uses a WiFi network and has many services to improve the learning process that makes the M-learning system a complete system that includes SMS, announcement, homework, contest service and feedback for learners. The main service in the system is the testing part which includes a new idea in education that uses the next generation of technologies. The advanced system is good and friendly and can improve distance learning systems. The access point used to establish a wireless network covers vast areas, making the service widely available to users. The most important individuals involved in the research are teachers, students and educational institutions such as universities, schools, institutes or anyone looking for the right m-learning that fits their requirements [8].

\subsection{The second aspect: Electronic tests}

Electronic tests are the continuous educational process aimed at evaluating the student's performance remotely using the Internet. It is characteristic easy to set up and implement, they can be applied simultaneously or at different times to a large group of individuals and in different places, they can be sent by mail or included in sites.

Feedback is an opportunity to learn and an important component of assessment in any learning environment. It enables students to identify gaps in their learning. In addition, it helps teachers adapt their learning designs to students' needs. Systems can play an important role in designing reflux systems In the classroom, learners and teachers can interact easily. Students can ask questions freely and teachers usually know if students understand basic concepts or problemsolving techniques. Feedback is an important element in this interaction. Furthermore, learning materials can be continuously improved using information from the interaction between lecturers and learners, leading to a more efficient and effective way of developing a course that can provide feedback to authors during the development of virtual course and learners during learning. In the current generation of elearning systems, comments that are produced automatically are few, mostly encrypted, not very valuable, and are used almost exclusively in question-and-answer situations [9].

Feedback describes any communication or action that is given to inform learners of the accuracy of the response, usually to an instructional question. In general, feedback compared actual performance to some standard performance. In technology-assisted learning, information is provided to the learner after any input, in order to shape learner perceptions. Information provided through comments in the instructions may include not only correct answers, but also other information such as accuracy, timing, learning guidelines, motivational messages, basic materials, sequence instructions, critical comparisons, and focus on learning. Feedback is given in the form of hints, information and recommendations.

\subsubsection{Studies that dealt with this aspect}

Amasha,M. (2010) See electronic tests is one of the computer technologies that can be adapted to overcome some of the difficulties that hinder the implementation of paper tests or to adapt them to provide other channels to increase the student's scientific achievement and consolidate information and develop self-learning skills [10].

\section{THE PROPOSED SYSTEM}

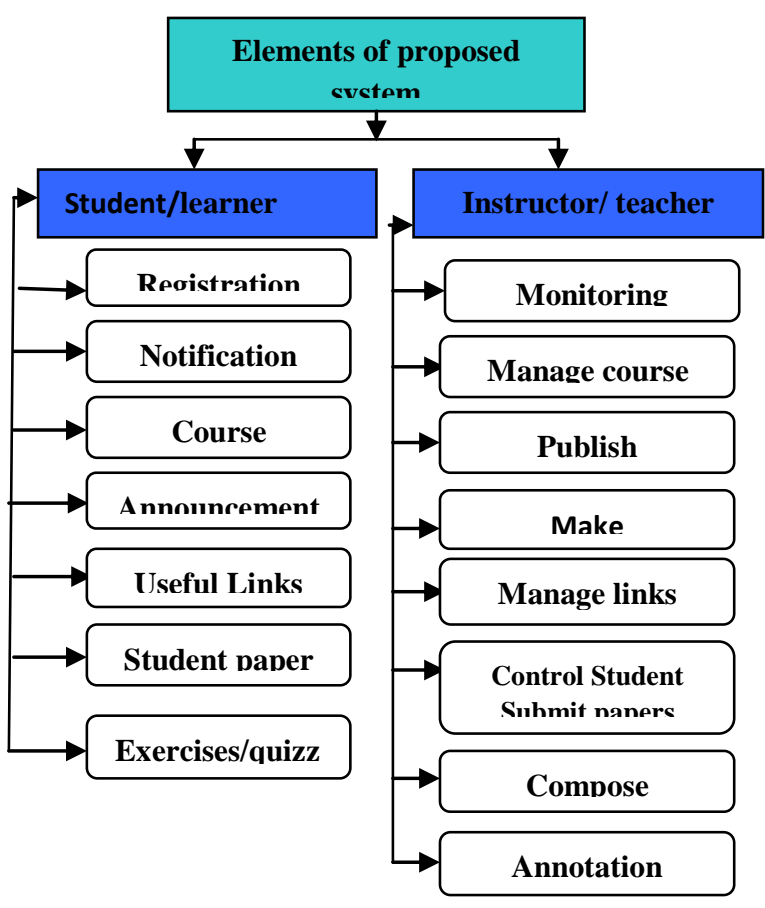

Figure (1) Showed Elements of proposed system 
Proposed model: provides the student with two kinds of contents

- Learning content

- Assessment content

Each content has different types of services such as:

Learning services: provide

- Registration

- course documents (is a repository for files that the instructor have made available to the student as a part of your course)

- announcements (displays information to the students that the instructors of the course want him to know)

- links (displays a list of useful URL links that have been identified by the course instructors)

- $\quad$ student papers (students can post/upload requests files to the instructor)

Assessment services: provide exercises and quizzes for evaluation of the student knowledge .During the learning process.

- On other hand, system allows instructors to :

- Insert description: Add the word file which contains the terms and their characterization.

- monitoring the students' performance

- Add students: The instructor adds student.

- Delete student.

- Publish documents in any format (Word, PDF, Video,) to the students.

- Manage a list of useful links.

- $\quad$ Compose exercises/quizzes.

- Make announcements.

- And have students submit papers.

\section{PROPOSED SYSTEM}

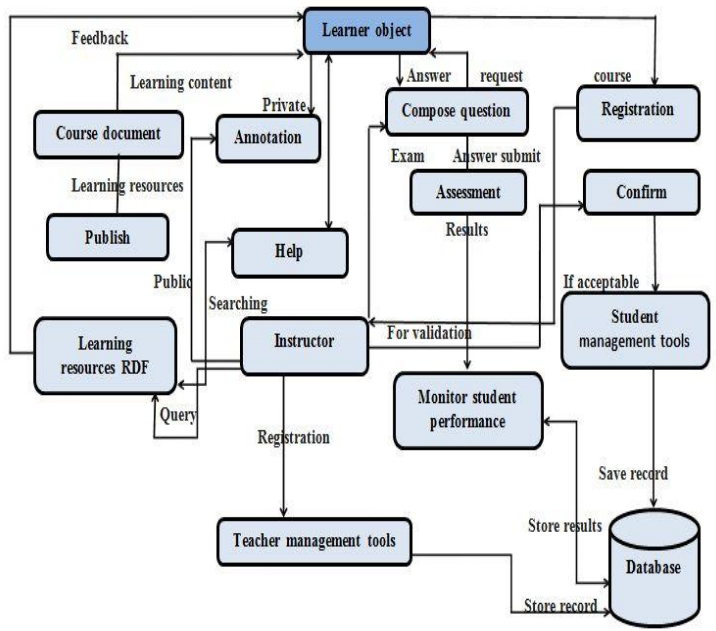

Figure (2) Showed proposed system
The research was based on the basic stages:
1- Analysis Phase
2- Design phase
3- Implementation phase

First: the analysis phase of the system This phase includes three sub-phases

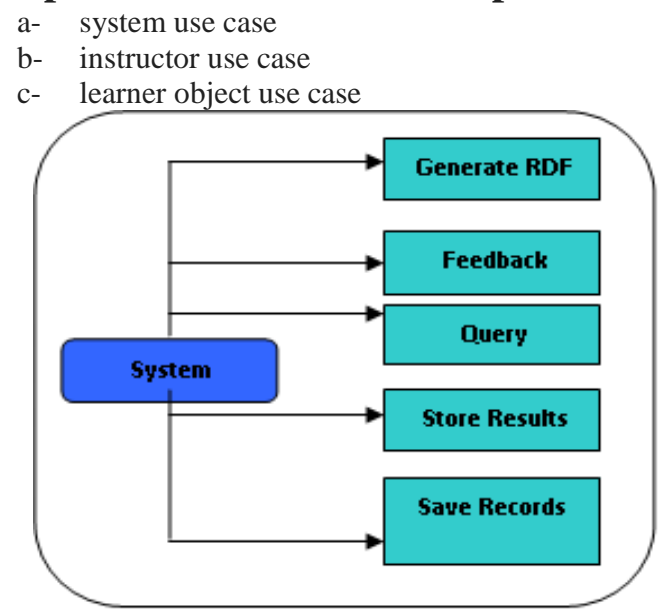

Figure (3) Showed system use case
a- system use case
b- Use case diagram of instructor,
c- Learner object use case diagram

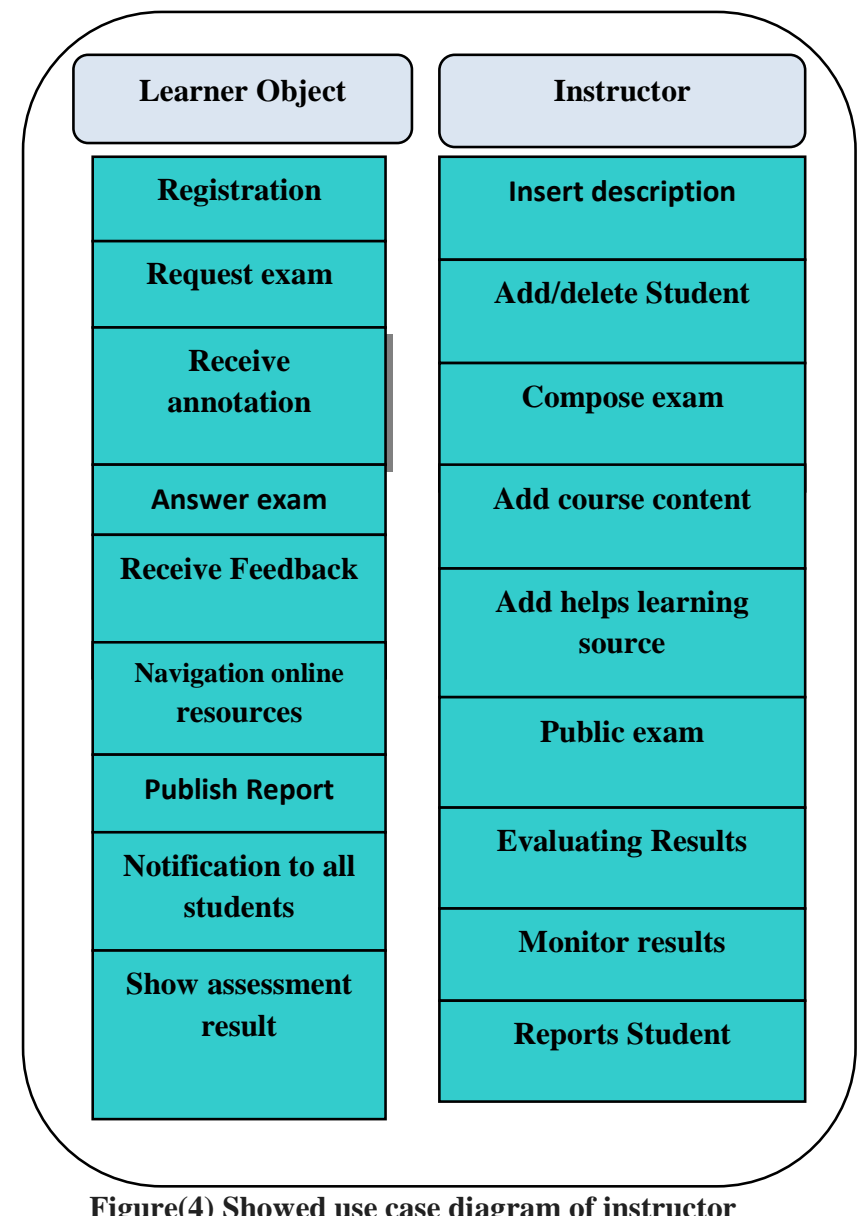

Figure(4) Showed use case diagram of instructor

Figure (4) Showed use case diagram of instructor, 
Learner object use case diagram

\section{Second: the design phase of the system}

-User Interface: The most important components where the interaction between the student and the instructor, and is the final form, there is a set of criteria that were taken into account when designing that interface is:

- Use terms that are easy to understand by the user.

- The interface is not very complex.

- Consistency of both colors and shapes to attract user attention.

- The application's main interface contains two components, user name and password and it contains two interface:instructor interface, Student interface.

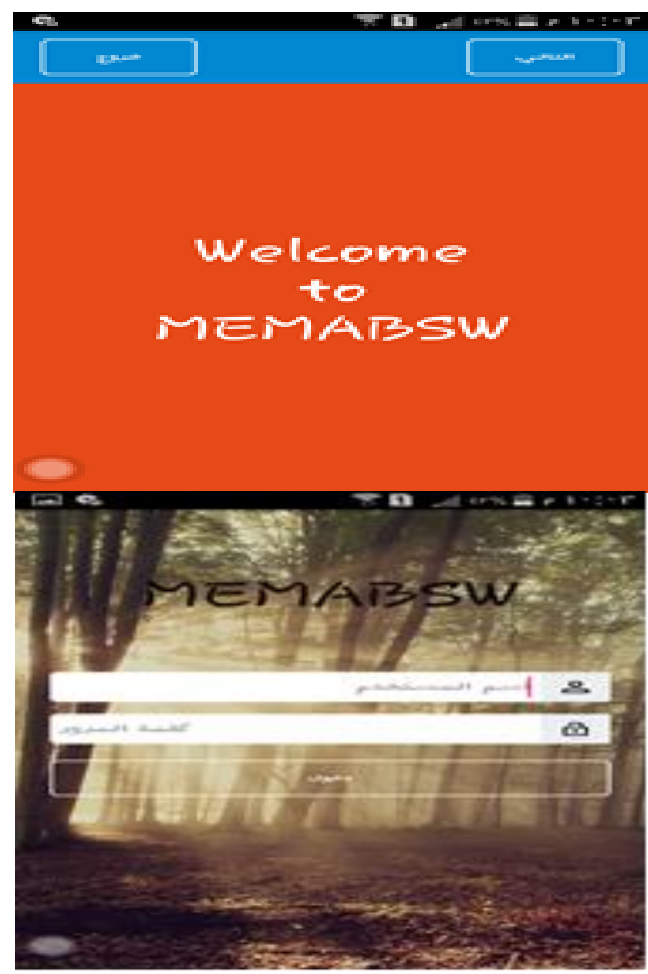

Figure (5) Showed main interface of application

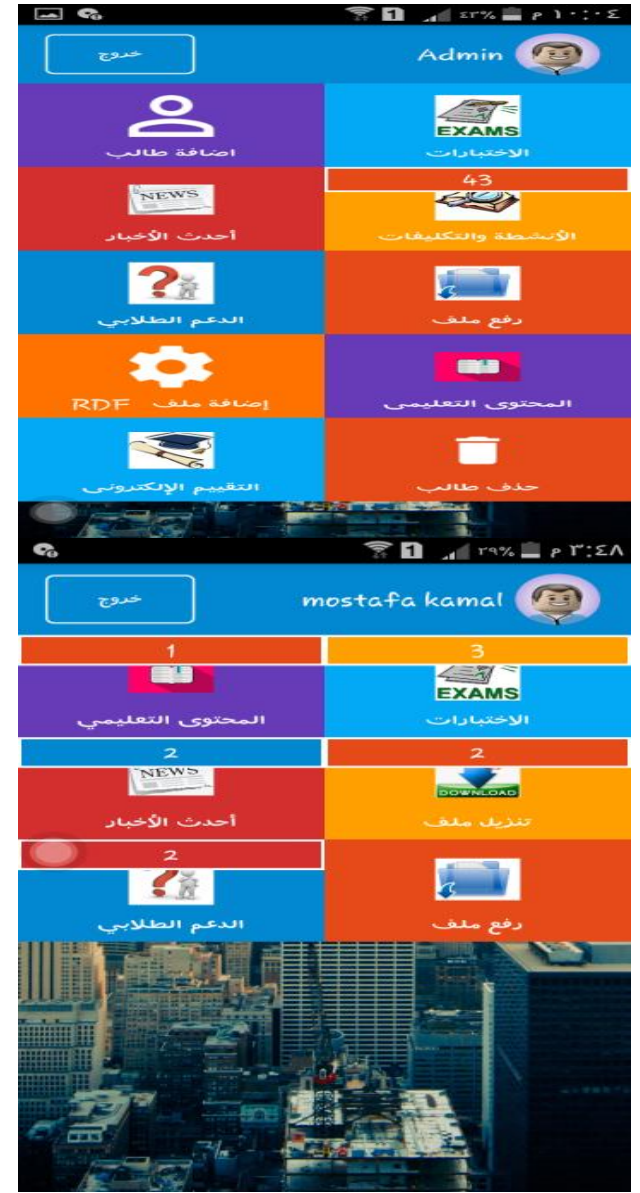

Figure (6) Showed instructor and student interface

\section{Third: Implementation phase}

The research used the following programs, languages and tools in the design of the proposed:

1- Adobe Photoshop CS6 for design

a. Manufacturer: Adobe

b. Use: It is used in the design and makes some adjustments to the images used in the proposed system, in order to output them appropriately.

c. Advantages: Helps to obtain images with certain specifications and characteristics depending on the needs of the user, and according to the modifications or designs.

d. Disadvantages: requires dealing with it to the training in advance, due to the multiplicity of tools.

2- Coding java, Asp.net for web services

a. Java script: Is now used in many fields more easily and simpler and also features that their products can be run on any device and does not require special programs to work Browsers can also be easily converted to applications running on mobile devices (mobile, tablet).

b. Asp.net: is a free web framework for building great web application and web sites using Html, css and JavaScript. 


\section{3- Dot net RDF}

a. A complete library for parsing, managing, querying and writing RDF.

b. A suite of command-line and GUI tools for working with RDF under Windows

c. Free and Open Source under a permissive MIT license

\section{IMPLEMENTATION}

\subsection{The research sample:}

A group of fourth-year students were selected randomly by the Computer Teacher Preparation Department at the Faculty of Specific Education in Damietta.

\subsection{Actual application of the experiment}

The use of the proposed application was also applied to the students of the experimental group. The application of the research tools to the students of the experimental group, and the application of the achievement test in order to obtain the students' grades. The statistical process needed to obtain the average scores of the students of the pre and post test were compared to obtain the results of the practical application of the research experiment.

To answer the first question of the research questions:

What is the proposed scenario for application based on mobile learning technology to manage electronic tests?

Researchers have followed the basic stages of designing described previously.

The researchers took into account the opinions agreed upon by the experts. They also presented the proposed design to the arbitrators to express their opinions through the arbitration form for the proposed system. Their consent after taking notes and making some of the amendments mentioned in the forms.

The proposed system was applied to the research sample, after the approval of the arbitrators by the validity of its application.

To answer the second question of the research questions:

What is the effectiveness of the proposed application based on mobile learning technology for electronic tests management?

Researchers prepared a questionnaire to measure the effectiveness of the proposed application, which includes four axes: accuracy, Information enrichment, feedback and electronic interaction.

The questionnaire was presented to a group of students. The students' responses were determined in the light of three measures: "Very agree, agree, and not agree ". The results were as follows:
Results for the first axis: Accuracy

\begin{tabular}{|c|c|c|c|c|c|c|c|c|}
\hline $\begin{array}{c}\text { Accuracy } \\
\text { axis }\end{array}$ & \multicolumn{2}{|c|}{$\begin{array}{c}\text { Very } \\
\text { agree }\end{array}$} & \multicolumn{2}{|c|}{ agree } & \multicolumn{2}{|c|}{$\begin{array}{c}\text { Not } \\
\text { agree }\end{array}$} & $\begin{array}{c}\text { Chi- } \\
\text { square }\end{array}$ & sig \\
\cline { 2 - 7 } & F & $\%$ & F & $\%$ & F & $\%$ & & \\
\hline $\begin{array}{c}\text { The } \\
\text { application } \\
\text { performs } \\
\text { its } \\
\text { functions } \\
\text { without } \\
\text { errors }\end{array}$ & 18 & 90 & 2 & 10 & - & - & 29.2 & $\mathbf{. 0 0 0}$ \\
\hline
\end{tabular}

Table (1) shows the frequency, percentage and Chi-square calculated and the level of significance of the Accuracy axis in the effectiveness of the proposed application

Table (1) shows the following:

Calculated Chi-square values for all resolution statements of the Accuracy axis of the proposed application effectiveness is greater than the Chi-square at the significance level (0.05) and the degrees of freedom (1) and for the benefit of the response is very agree indicating that the difference between the expected frequency and the expressions of the expressions is statistically significant, It is not due to coincidence, All members of the research sample emphasized the importance of these items for the Accuracy axis is evident from the choice of most of the response is very agree.

Results for the second axis: Enrichment information Table (2) shows the frequency, percentage and Chi-square calculated and the level of significance of the Enrichment information axis

\begin{tabular}{|c|c|c|c|c|c|c|c|c|}
\hline \multirow{2}{*}{$\begin{array}{c}\text { Enrichment } \\
\text { information }\end{array}$} & \multicolumn{2}{|c|}{$\begin{array}{c}\text { Very } \\
\text { good }\end{array}$} & \multicolumn{2}{|c|}{ agree } & \multicolumn{2}{|c|}{$\begin{array}{c}\text { Not } \\
\text { agree }\end{array}$} & $\begin{array}{c}\text { Chi- } \\
\text { square }\end{array}$ & sig \\
\cline { 2 - 7 } & F & $\%$ & F & $\%$ & F & $\%$ & & \\
\hline $\begin{array}{c}\text { The } \\
\text { application } \\
\text { provides a } \\
\text { variety of } \\
\text { sources } \\
\text { relevant to } \\
\text { educational } \\
\text { content }\end{array}$ & 18 & 90 & 2 & 10 & - & - & 29.2 & $\mathbf{. 0 0 0}$ \\
\hline
\end{tabular}

Table (2) shows the following:

calculated Chi-square values for all resolution statements of the Enrichment information axis of the proposed application effectiveness is greater than the Chi-square at the significance level (0.05) and the degrees of freedom (1) and for the benefit of the response is very agree indicating that the difference between the expected frequency and the expressions of the expressions is statistically significant, It is not due to coincidence, All members of the research sample emphasized the importance of these items for the Enrichment information axis is evident from the choice of most of the response is very agree. 
Results for the third axis feedback

Table (3) shows the frequency, percentage and Chi-square

Calculated and the level of significance of the feedback axis

\begin{tabular}{|c|c|c|c|c|c|c|c|c|}
\hline $\begin{array}{c}\text { feedback } \\
\text { axis }\end{array}$ & \multicolumn{2}{|c|}{$\begin{array}{c}\text { Very } \\
\text { good }\end{array}$} & \multicolumn{2}{|c|}{ agree } & \multicolumn{2}{|c|}{$\begin{array}{c}\text { Not } \\
\text { agree }\end{array}$} & $\begin{array}{c}\text { Chi- } \\
\text { square }\end{array}$ & sig \\
\cline { 2 - 7 } & F & $\%$ & F & $\%$ & F & $\%$ & & \\
\hline $\begin{array}{c}\text { The } \\
\text { application } \\
\text { provides } \\
\text { instant } \\
\text { feedback to } \\
\text { students } \\
\text { that } \\
\text { support the } \\
\text { learning } \\
\text { process }\end{array}$ & 20 & 100 & - & - & - & - & 40 & $\mathbf{. 0 0 0}$ \\
\hline
\end{tabular}

Table (3) shows the following:

calculated Chi-square values for all resolution statements of the feedback axis of the proposed application effectiveness is greater than the Chi-square at the significance level (0.05) and the degrees of freedom (1) and for the benefit of the response is very agree indicating that the difference between the expected frequency and the expressions of the expressions is statistically significant, It is not due to coincidence, All members of the research sample emphasized the importance of these items for the feedback axis is evident from the choice of most of the response is very agree.

\section{Results for the fourth axis: Electronic interaction}

Results shows the following: calculated Chi-square values for all resolution statements of the Electronic interaction axis of the proposed application effectiveness is greater than the Chi-square at the significance level (0.05) and the degrees of freedom (1) and for the benefit of the response is very agree indicating that the difference between the expected frequency and the expressions of the expressions is statistically significant, It is not due to coincidence, All members of the research sample emphasized the importance of these items for the Electronic interaction axis is evident from the choice of most of the response is very agree.

\section{First hypothesis validity test:}

To evaluate the validity of the first hypothesis, which states that "there are no statistically significant differences at the level of 0.05 between the grades of students in the applied of the pre and post test of the knowledge side of the computer networks for the benefit of the post-applied"

The researchers applied the T-Test to indicate the difference between the average scores of students for the pre and post measurements for the results of the knowledge achievement test using the SPSS program. The following table presents the results of the application of the test.
Table (4) demonstrates the results of the applied of the achievement test.

\begin{tabular}{|c|c|c|c|c|c|c|}
\hline Group & test & Mean & $\begin{array}{l}\text { Standard } \\
\text { deviation }\end{array}$ & df & $\mathbf{T}$ & Sig. \\
\hline \multirow{2}{*}{$\begin{array}{l}\text { The } \\
\text { experi- } \\
\text { mental }\end{array}$} & Pre & 4.1500 & \multirow[b]{2}{*}{1.55597} & \multirow[t]{2}{*}{19} & \multirow[b]{2}{*}{43.113} & \multirow[b]{2}{*}{.000} \\
\hline & Post & 19.1500 & & & & \\
\hline
\end{tabular}

By comparing the actual level of significance with the specific significance level 0.05 it is clear that the actual level of significance is lower than the predetermined level, so we reject the null hypothesis.

It is clear from the above table that the average grade of students in the post application is greater than the average grade of students in the pre applied in the achievement test (19.1500) while the average grade of students in the pre applied (4.1500). The results indicate that there is a statistically significant difference at 0.05 between the average score of the students in the study sample in the two dimensions (the pre-post) for the benefit of the post applied and that this difference is significant and not due to the chance factor.

The calculated value of (t-test) (43.113) and the degrees of freedom (19) indicate the high level of achievement of students after learning using the proposed web-based system for the management of educational mobile applications. The researchers explain this distinction between pre and post measurements due to the effective impact of the proposed application in building students' knowledge.

\section{Testing the validity of the second hypothesis:}

To evaluate the validity of the second hypothesis, which states that there are positive trends among the students of the experimental group (which study the course of the networks using the proposed system) towards the use of the proposed system. The researchers conducted a questionnaire containing (13) words that measure students' attitudes toward using the Proposed application. The value of Chi-square was calculated to calculate the level of significance of students ,The results showed that calculated Chi-square values for all resolution statements is greater than the Chi-square and for the benefit of the response is very agree indicating that the difference between the expected frequency and the expressions of the expressions is statistically significant, It is not due to coincidence, All members of the research sample emphasized the importance of these items is evident from the choice of most of the response is very agree. 'computer teachers' views towards the proposed system. The results show: There are positive attitudes students towards the use of the proposed application. 


\section{RESEARCH RESULTS}

The results showed the following:

- There are statistically significant differences at level 0.05 between the average scores When pre and post applying the achievement test

- There are positive trends among experimental group students (which study the network course using the proposed application) towards the use of the proposed system.

- There is the effectiveness of the proposed system to assess the learner and to get feedback and show the shortcomings of the learner that measure target at 0.05 level of significance.

- The effectiveness of the proposed application based on mobile learning technology for electronic tests management

- The study stressed the importance of using the proposed application for its benefits.

\section{SEARCH RECOMMENDATIONS}

- In the light of the above, the research recommends that:

- Importance of interest in the proposed application and work on its development.

- Benefit from the proposed system and disseminate it in teaching the rest of the materials to help students in the process of learning and get immediate feedback and electronic evaluation.

- The need to design other models of the proposed system to serve different disciplines.

- To allow students to participate positively in the educational process and away from traditional methods so that their skills grow effectively.

- The need to direct the efforts of researchers to serve and solve the problems of society and not just theoretical studies.

\section{CONCLUSION AND FUTURE WORK}

Of all the above, the importance of the proposed application of its benefits is clear. As for the future scope, we will try to develop this proposed system to help teach the rest of the materials to help students learn, get instant feedback and eevaluation

\section{ACKNOWLEDGMENTS}

The researchers extend their sincere thanks and appreciation to all those who assisted them in the various stages of research from experts and specialists in the field of computer science and technology education.

\section{REFERENCES}

[1] Prashant,B.(2014).FromTeaching Learning to Assessment: MOODLE experience at B'School in India .Vol(11),pp 857-865.

[2] Qwaider,W.(2012). Semantic Web Technologies Applied to E-Learning System. International Journal of Computer Applications(888-975), 47(10), pp 12-17.

[3] Paulins,N., Balina,S.\& Arhipova,I.(2015). Learning Content Development Methodology for Mobile Devices, Procedia - Social Behavioral Sciences, Vol(43), pp147153

[4] Sarrab, M. , Elgamel, L. \& Aldabbas, H. (2012). MOBILE LEARNING (M-LEARNING) AND EDUCATIONAL ENVIRONMENTS .International Journal of Distributed and Parallel Systems (IJDPS), 3(4) ,pp 31-38.

[5] Alzaza, N.\& Yaakub, A.(2011). Students' Awareness and Requirements of Mobile Learning Services in the Higher Education Environment . American Journal of Economics and Business Administration, 3 (1),PP 95 100 .

[6] Mahat, J., Ayub, A.\& Ayub, S. (2012). An Assessment of Students' Mobile Self-Efficacy, Readiness and Personal Innovativeness towards Mobile Learning in Higher Education in Malaysia. Procedia - Social and Behavioral Sciences , INTERNATIONAL DUCATIONAL TECHNOLOGY CONFERENCE IETC2012,64,PP284 - 290

[7] Castillo, A., Clunie, C., declunie, G.\& Rodríguez, K . (2013) . A system for mobile learning: a need in a moving world . 2nd World Conference on Educational Technology Researches , Procedia - Social and Behavioral Sciences,(83), pp 819-824 .

[8] Cavus, N. \& Al-Momani, M. (2O11) . Mobile system for flexible education . Procedia Computer Science, (3), pp 1475-1479.

[9] Sameh, A. (2009). Ontology-Based Feedback E-Learning System for Mobile Computing. Proceedings of the European Computing Conference , pp. 479-488.

[10] Amasha ,M.(2010). Towards a software package for computer teachers to prepare and design electronic tests, a study magazine in curriculum and educational,2(2),PP.209-254. 